\title{
Mobile Addiction and associated factors amongst youth
}

\author{
Anuja Deshpande ${ }^{1}$ \\ ${ }^{1}$ Assistant Professor, Department of Psychology, Maniben Nanavati Women's College, Mumbai. \\ E-mail-anuja185@gmail.com
}

\begin{abstract}
In today's era Addiction is not restricted to chemical or natural substances. Behavioural addiction is an emerging addiction noted these days. Technological Advancements are changing rapidly and new technology becomes available easily - something which is contributing to upswing of excessive mobile phone use. This is a simple review, based on empirical evidence available that focuses on the dilemma of using the correct term for mobile phone addiction. The diagnosis dilemma exists due to inequity in the measurement and description of the forms of mobile phone abuse. The article also tries to highlight how young minds are impacted by this phenomenon; and the various physical and psychological ill-effects associated with it.
\end{abstract}

Keywords : Mobile phone, Addiction, Youth, Risk association

\section{INTRODUCTION}

In today's world addiction is no longer restricted to alcohol or substance use. Behavioral addiction among youth is an increasing trend noted in the recent past. Researchers define technological addictions as a subset of behavioral addictions - one that involves human -machine interaction; and which develops when people become dependent on a device to reduce negative mood states or increase positive consequences [1-2].

Different experiences fall under technology addiction viz. Internet Addiction, Gaming Addiction, Mobile Addiction, Smartphone addiction, WatsApp Addiction, Social Media Addiction, Candy Crush Addiction etc. Some of these addictions come under the umbrella of Mobile addiction. Mobile Addiction is referred to differently by different authors. Typical terms include Smartphone addiction, Mobile phone overuse, Mobile phone dependence and Problematic mobile phone use among others. The concept of addiction to mobile phone use was introduced at first by Bianchi and Phillips [3] and has since gained tremendous acceptance and research.

Mobile phones have become a central part in students' lives because they are multi-purpose. This multi-function device is now easily available to the hands of young minds; and at a click it allows them to explore applications which provide new and varied functions. Smartphones have become easily available and affordable today. Many applications are available $24 / 7$ and are easily downloaded for free - a likely factor that makes individual dependent on a mobile phone. According to Hopeton and Leith [4] many participants use phones for clicking photos, as an alarm clock and to play 
games. The tendency to use mobiles for many purposes was found more among younger people.

In a study, it has been argued that mobile phones are popular among students because they provide an easy platform to increase their social communication [5]. On the other hand, yet another study suggested that college students use more social networking sites to maintain existing friendships rather than to make new friends [6]. Bianchi and Phillips [3] reveal that the highest level of problematic mobile phone use is most found among youth. Upon reviewing literature on Smartphone addiction among youth, a number of problems and methodological issues may be recognized. There is no uniformity in the definition of Mobile phone addiction among studies because of

a) The variety of addiction symptoms associated with Smartphone use;

b) The wide variety of new Smartphone functions; and

c) The different problematic outcomes associated with Smartphone addiction

This is further compounded by the fact that Mobile phone addiction may not produce observable signs or symptoms; such as physiological indications of cravings which is easily seen or observed in substance dependent addict. Indeed, the addicted individual may appear to be working in a normal and socially acceptable way. But the provisions are made for Mobile or cell phone addiction as a common disorder that merits inclusion in new classificatory systems - ICD-11 and DSM-5 [7]. It fulfills the diagnostic components:

- Excessive use- often associated with a loss of sense of time or a neglect of basic drives.

- Withdrawal, including feelings of anger, tension and/or depression when the phone or network is inaccessible.

- It also presents with symptoms of Nomophobia or Ringxiety.

- There is a development of Tolerance, including the need for new better cell instrument, more software or more hours of use and Negative repercussions', including lying (communifaking), arguments, poor achievement, social isolation and fatigue.

Authors have asserted that excessive usage of mobile phones does not bring in the rapid emotional changes associated with traditional forms of addiction; and so it can be considered abuse but not addiction [8]. Ahmed and others [9] assessed the pattern of mobile phone use among university students in Pakistan to explain the extent of addictive behavior in their usage. Results revealed that most students were able to set fixed priorities for their responsibilities and commitments and their mobile phone use. Their results also revealed that very few students exhibited extreme addictive behavior. Thus, they concluded that university students used their mobile phones within realistic limits and did not use beyond the limit that could lead to addictive mobile phone use.

Hooper and Zhou [10] investigated the various types of behavior associated with mobile use. They conducted a test in six behavioral categories addictive, compulsive, habitual, dependent, mandatory and voluntary behavior. Results highlight that mandatory behavior was most strongly associated with type of use, while addictive behavior was the least associated. The results also showed that mobile phone use could be regarded more as mandatory, voluntary or dependent behavior than habitual, compulsive or addictive. Walsh and others [11] examined activities of university students regarding mobile phone usage. They also attempted to understand if 
the facts compared with standard behavioral addiction criteria. Symptoms of behavioral and cognitive salience, conflict with other activities, euphoria, tolerance, withdrawal and relapse and reinstatement appeared at varying levels amongst respondent descriptions of their use of mobile phone. The study concluded that participants showed addictive use of mobile phone to some degree; and that they revealed indications of behavioral obsession. Another study by Tandon and Garg [12] on 269 students reported that the college students in India are highly addicted to the use of mobile phones and internet and excessively use technological services.

\section{COMMON HEALTH RISKS}

Mobile phone becomes problematic when its usage interferes with person's day to day activities as well as relationships. According to the research, mobile phone dependency has the ability to negatively impact significant areas of person's life. Some major disadvantage of excessive use of the mobile phones is as follow:

1. Financial issues (such as debt, due to high cell phone bills)

2. Poor Social Skills

3. Relationship issues

4. Car accidents

5. Job loss

6. Academic difficulties

7. Low self-esteem

Majority of studies have examined the physical and mental health effects of mobile phone radiation leading to cancer, nervous system disorders and adverse procreative effects. Heavy use is also associated with many orthopedic related problems like Text Claw Elbow and Text Neck and with posture. Constant use of Bright screens and/or small text leads to strain in the eye of users. Eye strain is common phenomena noted as 'focusing too much on the screen or due to continuous texting and playing games' as reported by the Center on Media and Child Health.

\section{Psychological Problems}

When faced with a person who is dependent on mobile phones, First is the dilemma - is the behavior addictive or compulsive. Keeping in mind both the aspects - i.e. - mobile phone usage can be addictive or compulsive; it has been found to cause problems like depression, restlessness, insomnia and anxiety.

Researchers have found that the frequency of mobile phone use is associated with mental health issues like sleep disorders and depression [13]. Others [14] have also found that the frequency of using message services is associated with the presence of psychological and behavioral symptoms; and this effect is mediated by selfperception and personality factors. Yet another study has explored internet addiction and text messaging addiction among adults and have found that both these conditions are strongly associated with depression [15].

Poor sleep patterns or insomnia was one of the most common issues seen. A study in Gothenberg, Sweden found out that high mobile phone use was associated with sleep disturbances and symptoms of depression. Reports by top sleep experts in The Daily Galaxy have raised serious concerns due to the more than sufficient evidence showing that radiation from headphones affects deep sleep [16]. 
Digital thumb is a troublesome problem which is caused due to continuous usage of fingers especially the thumb over the small keypad on the cell phones. Like Computer-related stress injuries, this ailment is occurs as students use the cell phone excessively. Repetitive strain injuries like digital thumb, that result from repetitive tasks (e.g. - typing on small buttons) has been mentioned by the Center on Media and Health as a'Downside of Cell Phones'. Similarly, loud music over the phone may be a contributing factor for hearing loss. The FYI Living study [17] reported that the response in a "distracted" listening test was late and of less amplitude in the group exposed to cell phones.

\section{CONCLUDING REMARKS}

Every new piece of technology has the potential to be both a boon and a curse. Mobile phones, while they have brought people closer and have enabled even the most remote person to access the internet and to engage in educational, recreational and social activities; unrestricted use has the potential to cause dependence. People with signs of dependence on or addiction to mobile phones display an array of health and mental health issues. They show signs of compromised functioning either in the presence of or due to the absence of the mobile devices - a clear indicator that the technology is being abused. As psychologists and alert citizens, it becomes our task to ensure that we do not allow ourselves to become dependent on mobile phones; as well as to help those already showing signs of addiction and dependence throw off the yolk of the device, and instead harness it to fulfill one's potential.

\section{REFERENCES}

1. Griffiths M. Internet addiction. The Psychologist 1999;12:246-50

2. Griffiths MD. Does Internet and computer "addiction" exist? Some case study evidence. Cyberpsychol Behav 2000;3(2):211-8.

3. Bianchi A, Phillips J. Psychological predictors of problem mobile phone use. Cyberpsychol Behav 2005;8(1):39-51.

4. Dunn HS, Dunn L. Gender standing mobile telephony women, men and their use of the cellular phones in the Caribbean. Retrieved from World Wide Web ; 2011. http://www.slideshare.net/grraph/raphaelgrignanimobilephoneusageamongstfrenchteenag ers

5. Hong FY, Chiu SI, Huang DH. A model of the relationship between psychological characteristics, mobile phone addiction and use of mobile phones by Taiwanese University female students. Comp Hum Behav 2012;28:2152-9.

6. Ellison NB, Steinfield C, Lampe C. The benefits of Facebook friends: Social capital and college students' use of online social network sites. J Comp Med Comm 2007;12(4):114368.

7. American Psychiatric Association. Diagnostic and Statistical Manual for the Classification of Psychiatric Disorders - $5^{\text {th }}$ edition (DSM-5). American Psychiatric Publishing ; 2014.

8. Ahmed I, Ramzan M, Qazi TF, Jabeen S. An investigation of mobile phone consumption patterns among students and professionals; is there any difference? Eur J Econ Finance Admin Sci 2011;39:136-43.

9. Baig A. Mobile Phone Addiction among Youth. Retrieved from http://www.academia.edu/5143404/; 2012.

10. Hooper V, Zhou Y. Addictive, Dependent, Compulsive? A study of mobile phone usage. Proceedings of the 20th Bled eConference: Merging and Emerging Technologies, Processes, and Institutions, June 4-6, 271-285; 2011. 
11. Walsh SP, White KM, Stephen C, Young RM. Keeping in constant touch: the predictors of young Australians' mobile phone involvement. Comp Hum Behav 2011;27:333-42.

12. Tandon A, Garg M. Mobile phone and internet adoption \& consumption patterns of college students in India. Elixir Marketing Mgmt 2012;55(2013):12754-9.

13. Sara $T$, Annika $H$, Mats $H$. Mobile phone use and stress, sleep disturbances and symptoms of depression among young adults-a prospective a cohort study. BMC Public Health $2011 ; 11: 66$

14. Igarashi T, Motoyoshi T, Takai J, Yoshida T. No mobile, no life: Self-perception and textmessage dependency among Japanese high school students. Comp Hum Behav 2008;24(5):2311-24.

15. Xi L, Watanbe J, Liu Q, Uji M, Shono M, Kitamura T. Internet and mobile phone text messaging dependency: Factor structure and Correlation with dysphoric mood among Japanese adults. Comp Hum Behav 2011;27:1702-9.

16. Bian M, Leung L. Linking loneliness, shyness, smartphone addiction symptoms, and patterns of smartphone use to social capital. Soc Sci Comp Rev 2015;33(1):61-79.

Acknowledgements - Nil.

Conflict of Interest - Nil.

Funding - Nil. 